\title{
Performance Evaluation of Embedded Transmission Tariff Models for Deregulated Electricity Market
}

\author{
Chiedozie Francis Paulinus-Nwammuo, Damian Obioma Dike*, Moses Izuchukwu Adinfono, \\ George Ogu
}

Department of Electrical Electronic Engineering, Federal University of Technology, Owerri, Nigeria

\section{Email address:}

paulinus.nwammuo@futo.edu.ng (C. F. Paulinus-Nwammuo), damian.dike@futo.edu.ng (D. O. Dike), mosesadinfono@gmail.com (M. I. Adinfono), georgeogu1975@gmail.com (G. Ogu)

${ }^{*}$ Corresponding author

\section{To cite this article:}

Chiedozie Francis Paulinus-Nwammuo, Damian Obioma Dike, Moses Izuchukwu Adinfono, George Ogu. Performance Evaluation of Embedded Transmission Tariff Models for Deregulated Electricity Market. American Journal of Electrical Power and Energy Systems. Vol. 6, No. 3, 2017, pp. 16-26. doi: 10.11648/j.epes.20170603.11

Received: March 16, 2017; Accepted: April 13, 2017; Published: June 1, 2017

\begin{abstract}
During the regulated power system era, the three major components of the power system are treated as a single entity and managed by same firm. Electricity was then treated more as a welfare commodity based on political patronage. With the wide adoption of deregulation, which resulted in the wholesome privatization and commercialization of the generation and distribution components, the transmission facility was left in the hands of the Government. Considering that this is a sure link between the other two, there is greater need to develop a mechanism for its appropriate tariff determination in order to ensure fairness to all its users. A significant deficiency in its pricing is the non-inclusion of the reactive power component, which is seriously needed to ensure system stability. This work involved the performance evaluation of four embedded transmission pricing models. Based on the need to build-in payment for reactive power which is necessary to ensure system stability, further presents an improved postage stamp transmission tariff-pricing model that incorporates both real and reactive component of power. The Postage stamp method calculates all the network costs and divides it by the overall power transmitted through it. This single rate is charged to users irrespective of the source and destination of power transactions. This is a simpler, fairer and easier to implement approach for computation using Matlab and Excel Software packages. The proposed method gave average price of $29.48 \$ / \mathrm{hr}$ as against $\$ 27.75 / \mathrm{hr}$ when reactive power was not included for the South African 18-Bus System. This showed slight improvement when compared to the conventional approach where reactive power was not included in the power transaction. It may be applied in developing countries like Nigeria where Government is gradually pulling out of full funding of the power sector, and seeking for technically sound and financially buoyant local and foreign firms to take over significant part of the sector. The distance flow based and cost flow based methods showed very higher costs which may not be suitable for developing countries at their present stage of deregulation due to very low income per capita and low level of industrialization.
\end{abstract}

Keywords: Deregulated Environment, Postage Stamp Method, Reactive Power, Real Power and Transmission Pricing

\section{Introduction}

The traditional power system that existed over the years involved an aggregation of the three major components of the power system as a single entity. The central governments of most countries realizing the very important role electricity plays in her socio-economic wellbeing and socio-political stability took full charge of the operation, control and management of all the power system components generation, transmission and distribution - as a vertically integrated system. This arrangement has worked for some time in the past where the citizenry take whatever is offered to them as they have no option, but sparingly make requisite payment. Many issues were not apparent due to the fact that majority of the populace lived in abject poverty without the necessities of life that require electricity for their operation. 
With increased level of rural to urban migration, improved literacy level and globalization made possible by the emergence of information communication technology facilities in most of the urban and semi-urban towns, there is now greater demand for electricity. Equally, many governments are now struggling to meet-up with the current demand of their citizens, and have joined the developed countries to privatize, commercialize and deregulate most previously protected essential services provision like communications and electricity. The privatization and partial sales of government majority hold in the telecommunication industry in Nigeria, for instance, was remarkably successful and created many jobs as well as raised the country's gross domestic product. The same model has not worked in the electricity sector in Nigeria because it is somewhat differently structured and need different approach. There is no way the privatized generation and distribution systems can work without a functional and well-funded transmission grid since this is the interlinking system between the other two.

In view of the foregoing, a lot of literature has emerged on the various cost allocation methods in connection with the transmission of electricity. According to [1], the objective of transmission pricing is to recover all or part of the existing and new cost of transmission system. In addition, pricing of transmission services plays a crucial role in determining whether providing transmission services is economically beneficial to both the wheeling utility and the wheeling customers. With transmission as the interconnecting link between the generation and distribution, a players action has consequences to other players which makes it difficult to investigate the component prices to each transaction participant [2], [3].

Various pricing approaches for transmission was first proposed in [4], the author identified three different pricing approaches for electricity transmission namely; the rolled-in pricing methods, the incremental pricing method and composite embedded and incremental pricing method, a combination of the first and second methods [5]. In the rolled in method, all the cost are added up into a single cost making it impossible to distinguish between costs. Nevertheless, the costs calculated are shared between users [6]. The various roll-in methods are Postage Stamp Pricing, Contract Path Pricing, MW-Mile Method and MVA-Mile Method.

Postage stamp pricing entails that all transmission users would pay a single rate, which covers the transmission transaction that occurs within a defined region, not minding the contractual origin or destination of transmitted electricity. The same rate applies to all customers [7]. This method is the simplest among all embedded cost method and easy to implement. It does not require power flow calculations and is independent of the transmission distance and network configuration. The rate paid in this case is calculated by adding all network costs and dividing it with the system peak demand. The customer's transmission charge is the product of the postage stamp rate and the peak demand of that customer. Its simplicity of calculation made it popular among embedded cost methods used by electric utilities. Its drawback includes that it sends the wrong economic signal to transmission suppliers and users, as well as does not encourage sitting future investment or the efficient use of the transmission infrastructure [8], [9].

In Contract Path Pricing a virtual path is created between the point of injection and removal of electrical energy for a wheeling transaction. The contract path is usually selected without a formal power flow study to identify the 'dedicated' path for the given transaction [10]. Like the postage stamp method this one is also easy to implement, only the transmission facilities in the 'dedicated' transaction path are taken into consideration. More so, neither reverse flows nor parallel flows are considered [8], [11].

The MW-Mile Method also referred to as line by line method entails that the embedded cost be allocated based on the magnitude of the transacted power and the air distance (in miles) between the point of injection and removal of power. That is the product of the power due to the transaction and the distance this power travels through the network [1]. It still has all the drawbacks of the two above-mentioned methods [5], and is DC power flow based. MVA-Mile Method is an extension of the MW-Mile method only that in this case both real and reactive power are considered unlike in the MW-Mile where only real power is treated. A transaction leading to more reactive power loading will be asked to pay more than others [7].

The second transmission pricing method is the Incremental Transmission Pricing Method composed of Short-Run Marginal Cost Pricing (SRMC), Long-Run Marginal Cost Pricing (LRMC), Short-Run Incremental Cost Pricing (SRIC) and Long-Run Incremental Cost Pricing (LRIC). Transmission infrastructures have both fixed cost and variable cost operations. The incremental cost approach deals with the variable costs. This approach does not include the embedded costs of energy transactions. For calculation of the incremental prices, [4] proposed the following methods respectively:

A major motivation for the SRMC was to overcome the inefficiencies of fixed tariffs which fail to provide incentives for efficient energy usage. It assumes that all capacity is fixed [12]. Short-run marginal pricing scheme is based on establishing a price at each node called spot prices.

Regarding the economies of scale, SRMC does not cover the fixed costs of networks even in theoretical situations implying the need for additional charges.

LRMC scheme unlike SRMC includes the possibility of change for the transmission capacity. Long-run scheme implies that no costs are by definition fixed. All the factors characterizing production, transmission and consumption are to be variable therefore presenting an optimization problem which carries out calculations for the optimal cost transmission capacity. In general, long-run marginal costs are costs of changing the overall system capacity often represented in unit form. Such costs are also dependent on the estimation of the future energy consumption and peak loads [4], [5]. In this scheme, the marginal operating and reinforcement costs of the system are used to calculate the 
price for a transaction [1].

SRIC scheme is a different pricing scheme than the marginal methodologies because it differs in the terms of cost definition. While it may sound ambiguous, in incremental pricing methodology incremental transactions have to be evaluated unlike the computation of marginal costs in SRMC. All new expenses that may appear are incrementally added to the transactions that are established on the path of the energy transmission. A problem may occur in the compensation process of the real costs since revenues of this model cover only short-run costs assigned to specific transmission transactions. Authors propose the use of the optimal flow model (OPF) to determine all the constraints and stability issues for cost estimation.

LRIC is an extension to the SRIC; minor difference is that the costs of the reinforcement for the network on long run view. Such costs are characterized as cost emanating from changes between current transaction charges and long-term transaction plans [4] \& [5]. Composite Embedded/Incremental Pricing incorporates existing system costs and the incremental cost of transmission transaction. It solves the common problems associated with both by combining their advantages. This seems applicable in theory but problematic in practice.

Presently most developed countries like USA that have practiced deregulation for a long time and electricity fully paid for by consumers use locational marginal pricing model for most of its transmission [13] while South Africa presently uses quasi postage stamp transmission pricing mechanism with distance flow based method [14]. It is expected that each country will apply a method that suits her level of deregulation and economic development.

\section{Mathematical Modeling}

Postage Stamp Method of transmission pricing: As the name implies, a fixed rate is charged to every customer in relation to a particular region, irrespective of the origin or destination of power movement. It is taken as an average since the total cost of the transmission facility divided by the overall power transmitted through it, gives rise to a unit cost per transmitted power unit. Only real power is considered.

For any transaction, the cost using the conventional postage stamp method is given by equation 1 :

$$
C_{p s}=\frac{T C}{8760} * \frac{P t}{P_{p e a k}}
$$

Where;

$T C$ : is the Annual Revenue Requirement (ARR) (sum of all transmission facility cost)

$P t:$ is the transacted power in MW

$P_{\text {peak }}:$ is the entire system load at the time of system peak load condition in MW [10].

This method is adjoined one of the simplest because the distance, point of origination and destination of load are not needed in its computation also load flow analysis is not required. This method assumes that the entire transmission network is used in delivering the power.

In the classical Postage Stamp methods of transmission cost allocation, only real power MW is used. This study improved on the conventional postage stamp method by incorporating reactive power component into the conventional approach. Therefore in the improved approach, to find the Postage stamp price of transmission for a particular transaction the reactive power component is incorporated at every point and given in the set of equations (2) - (6).

Firstly, the transmission cost is obtained in \$/year, this piece of information is to be obtained from the unit in charge of the transmission corridor or could be estimated in relation to the line reactance as can be seen in [14] \& [15]

$$
A v R R=\frac{T C}{8760}
$$

AvRR: Average Revenue Requirement (this gives the transmission cost per hour with units in $\$ / \mathrm{hr}$ )

The total power demand is obtained from the bus data information of the test system being used

$$
\operatorname{Tlp}=\operatorname{sum}\left(P_{d}\right)+\operatorname{sum}\left(j^{*} Q_{d}\right)
$$

To obtain the transacted power $P t_{i}$, real and reactive power components are incorporated and are separately calculated for all the transactions.

$$
P t_{i}=\operatorname{transqtyMW}(i)+j * \text { transqtyMVAr }(i)
$$

Here the peak power demand is dynamic as it changes with every transaction due to the introduction of reactive power thus;

$$
P_{\text {peak }}(i)=P t_{i}+T l p
$$

The postage stamp transmission price for each transaction can be calculated using equation 6 .

$$
P_{s i}=A v R R^{*} a b s\left(\left(P t_{i}\right) / P_{p e a k}(i)\right)
$$

Where:

$P_{d}:$ is the real power demand at the various buses.

$Q_{d}$ : is the reactive power demand at the various buses.

transqty $M W$ : this is the real component of the power transacted across buses.

transqtyMVAr: this is the reactive component of the power transacted across buses.

$P_{\text {peak }}(i):$ this is the entire system load at the time of a transaction during system peak load condition(MW and MVAr included)

Contract Path Method: here the method does not consider the laws governing electron flow, it rather assumes that the transacted power follows a specified path, also power flow calculations is not required. The equation is given thus 


$$
\mathcal{C}_{c p}=P t\left(\frac{\sum \text { path } \mathcal{C}_{f}}{P_{\text {min_path }}^{* 8760}}\right)
$$

Where:

$\sum$ path $\mathcal{C}_{f}$ : this is the summation of annual revenue requirement of individual lines along the specified transaction path

$P_{\text {min_path }}$ : is the minimum value amongst the maximum long-term rating of the individual lines that make up the transmission line along the specified transacted path.

Distance flow Based Method: this method depends on the distance between transmission lines as well as the magnitude and direction of the power flow. In computation, power flow analysis is required. The power system analysis method used in this work is the Newton-Raphson method of power system analysis. The method is classified along the lines of real and apparent power and each is further grouped according to the direction of power flow, which was identified by [16] as Net reaction approach, Dominant approach and gross approach. This paper used the net reaction approach, as this makes more sense as equal and opposite forces cancel out and would eliminate double charging the parties involved. The expression for distance flow based method of transmission is given as [16]:

$$
C d f=\frac{T C \sum_{f}\left(P_{f}^{k}\right)_{T} L_{f}}{8760 \sum_{T}\left(\sum_{f}\left(P_{f}^{k}\right)_{T} L_{f}\right)}
$$

Where:

$P_{f}^{k}$ : Change in power flow in facility $\mathrm{f}$ due to user $\mathrm{k}$

$\left(P_{f}^{k}\right)_{T}$ : Change in power flow in facility $\mathrm{f}$ due to Transaction T

$L_{f}$ : Length of transmission line $\mathrm{f}$

Depending on the type of distance flow based method used, P could signify MW for real power or MVA for apparent power cases.

Cost flow based Method: this is similar to the distance flow based method, with the difference been that instead of the length of transmission line, the cost of the transmission line $C_{f}$ is used as in equation (8). Thus, it becomes [16]

$$
C_{c f}=\frac{T C \sum_{f}\left(P_{f}^{k}\right)_{T} C_{f}}{8760 \sum_{T}\left(\sum_{f}\left(P_{f}^{k}\right)_{T} C_{f}\right)}
$$

$C_{f}$ : cost of transmission line $\mathrm{f}$, also known as the ARR of the facility $\mathrm{f}$.

The algorithm for distance flow based and cost flow based transmission pricing methods are presented in [16].

\section{Implementation}

The developed algorithm utilized in the execution of Improved Postage Stamp Transmission Pricing is:

a Initialization: Input data such as annual revenue requirement of each line (ARR), real power demand $\left(P_{d}\right)$, reactive power $\operatorname{demand}\left(Q_{d}\right)$ at each of the bus, real power transacted, reactive power transacted as well as originating and destination bus of each transaction.

b Calculate the Total ARR of the transmission lines, TC

c Establish the Total Cost (Average Revenue Requirement) in $\$ / \mathrm{Hr}$; using equation 2

d Calculate the total load of the system ; using equation 3

e Obtain $P t_{i}$ (Transacted Power) for Transaction i; using equation 4

f Calculate the peak power for transaction i; using equation 5

g Calculate the transmission cost per transaction i; using equation 6 ,

h Check if number of transaction is exceeded, If No, Go back to step e, Else proceed to i.

i Display the transmission cost per transaction, for all transactions

j Stop.

The requisite flow chart derived from this algorithm is as shown in Figure 1.

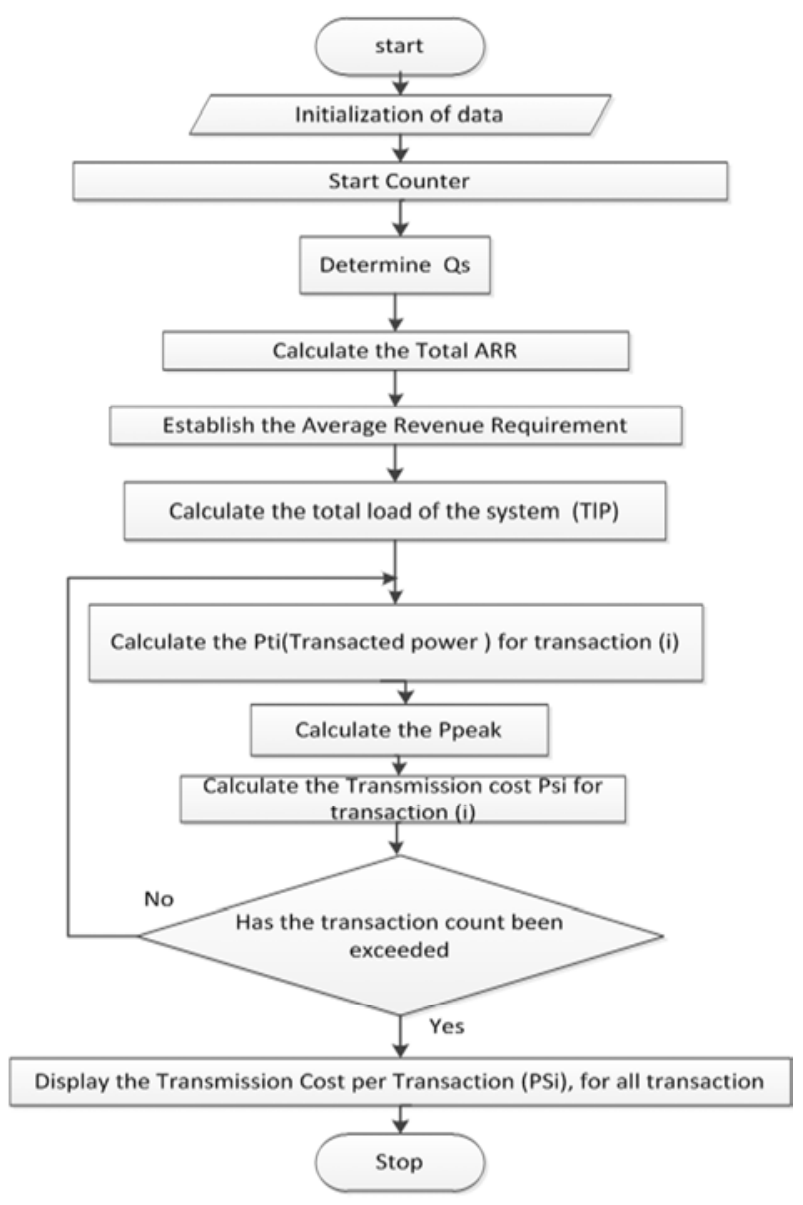

Fig. 1. Flow Chart of the improved postage stamp transmission pricing. 
The test data used in the implementation of the models used are:

a Power Transactions used for the 18bus-South African Test System [14].

b Bus and Line data for 18-bus South African Test System[14]

c Power Transactions data used for the 30-bus IEEE test system

d Bus data for IEEE 30-bus Test System [17]

e Adapted Line data for IEEE 30-bus Test System [15], [17] \& [18]

\section{Results and Discussion}

Simulations were performed using the various models discussed in the mathematical modeling section on the test data mentioned above. The results are presented in two cases for the South African eighteen bus and the Institute of Electrical and Electronic Engineering thirty (IEEE-30) bus, and are presented thus;

Case 1: In the South African 18 bus test system, four transactions were carried out. Transaction $1 \& 2$ involved only real power component in the transactions while transactions $3 \& 4$ involved both real and reactive power in the transactions. The results obtained after the power transactions were conducted using the conventional and proposed postage stamp method is presented in Table 1 and graphically represented in Figure 2.

In the 18-bus test system for transactions 3 and 4 respectively the proposed postage stamp method gave a higher cost of $29.59134 \$ / \mathrm{hr}$ and $49.21312 \$ / \mathrm{hr}$ as against $26.87365 \$ / \mathrm{hr}$ and $44.69993 \$ / \mathrm{hr}$ for the conventional postage stamp method, due to inclusion of real and reactive power components. While in transactions $1 \& 2$ the conventional method showed a slight increase of 17.93372 $\$ / \mathrm{hr}$ and $21.51184 \$ / \mathrm{hr}$ as against 17.77728 and 21.32434 $\$ / \mathrm{hr}$ for the proposed method. The implication is that those transactions that introduce reactive power and cause instability in the system are charged more while those transactions that lead to more stability are charged less.

Table 1. Postage stamp transmission pricing results for the 18-bus test system.

\begin{tabular}{lll}
\hline Transaction & \multicolumn{2}{l}{ Transmission cost } \\
\cline { 2 - 3 } No. & Proposed $\operatorname{method}(\mathbf{S} / \mathbf{h r})$ & Conventional Method (\$/hr) \\
\hline 1 & 17.77728 & 17.93372 \\
2 & 21.32434 & 21.51184 \\
3 & 29.59134 & 26.87365 \\
4 & 49.21312 & 44.69993 \\
\hline
\end{tabular}

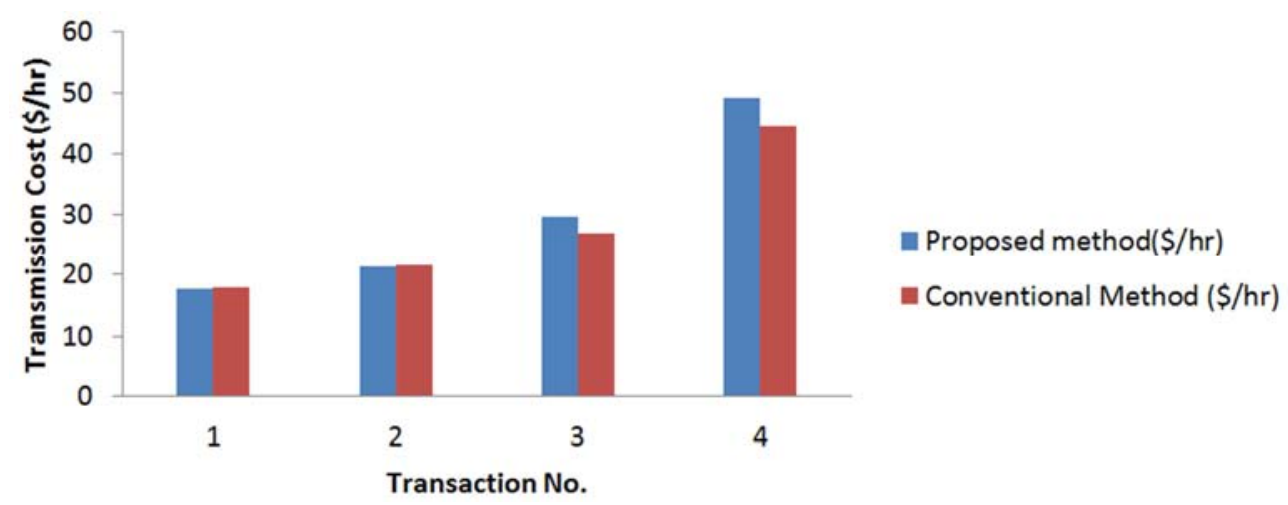

Fig. 2 The graphical representation of the 18-bus test system.

Appendix 1 and 2 give the results for the distance flow based and the cost flow based results for transmission pricing of the 18 bus test system respectively, which also shows the MW and MVA variants of the approaches employed.

Case 2: In the IEEE-30 bus system, four transactions were also conducted with the results obtained for both the conventional and proposed method shown in Table 4 and the graphical representation shown in Figure 3.

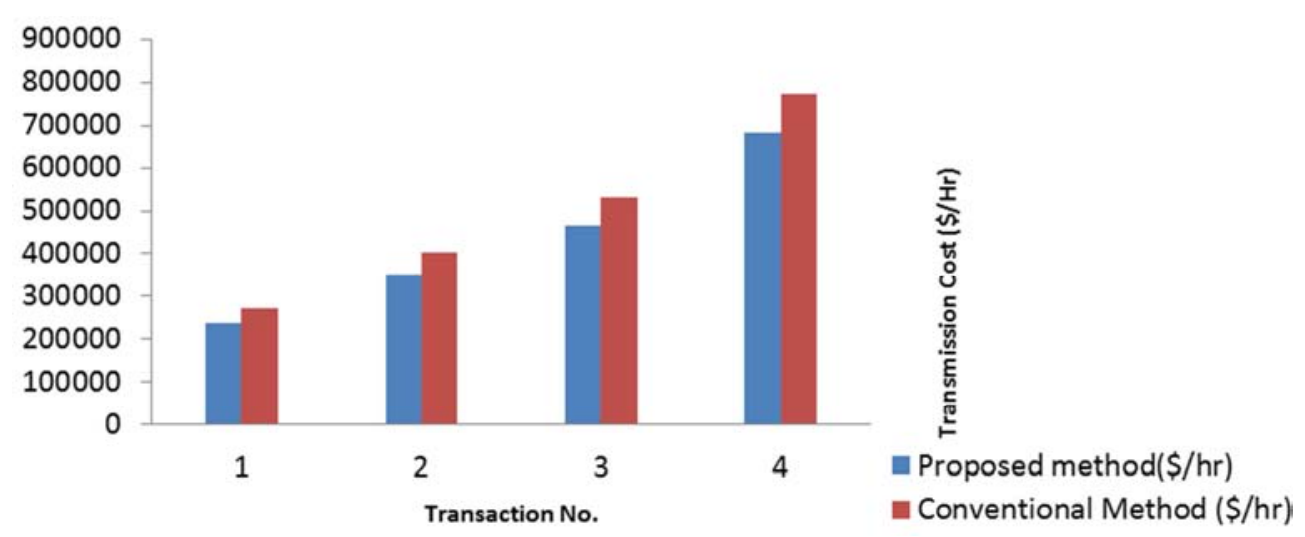

Fig. 3. Graphical representation of the result obtained for the IEEE-30 bus test system. 
Table 2. Result of conventional and proposed postage stamp method on IEEE-30 Bus system.

\begin{tabular}{lll}
\hline \multirow{2}{*}{ Transaction No. } & Transmission cost & \\
\cline { 2 - 3 } & Proposed $\mathbf{m e t h o d}(\mathbf{S} / \mathbf{h r})$ & Conventional Method (\$/hr) \\
\hline 1 & 237544.3 & 273717.1 \\
2 & 352298.3 & 404324.6 \\
3 & 464465.6 & 531014.5 \\
4 & 681310.7 & 773326.7 \\
\hline
\end{tabular}

In the IEEE-30 bus system, which served as the control the conventional postage stamp showed an increase against the proposed method as was expected as reactive power was not injected into the system. This was achieved with the proposed postage stamp MATLAB syntax

Appendix $3 \& 4$ are the results for the distance flow based method and the cost flow based method of transmission pricing for IEEE-30 bus test system showing the MW and MVA variants for the four transactions. In Table 5, lines 4-12, 6-9, 6-10, and 28-27 returned zero for the distance flow based calculation because these are the positions of the transformers and their length are taken as zero initially. The columns with zero values for lines 12-16 and 10-21 gave very negligible values and as such were taken to be zero.

Table 3. 18 bus test system result for all four transactions.

\begin{tabular}{llll}
\hline \multirow{2}{*}{ Transmission Pricing Method (\$/hr) } & \multicolumn{3}{l}{ Transaction No. } \\
\cline { 2 - 4 } & $\mathbf{1}$ & $\mathbf{2}$ & $\mathbf{3}$ \\
\hline Conventional Postage Stamp & 17.93372 & 21.51184 & 26.87365 \\
Proposed Postage Stamp & 17.77728 & 21.32434 & 29.59134 \\
Contract Path method & 53.4 & 60 & 41.38 \\
Distance flow based (MW) & 702.7406 & -1009.3 & 8942.69 \\
Distance flow based (MVA) & 1219.54 & -1646.66 & 7666.718 \\
Cost flow based (MW) & 1075.164 & -1867.07 & 10645.76 \\
Cost flow based(MVA) & 1729.251 & -2211.37 & 712.7984 \\
\hline
\end{tabular}

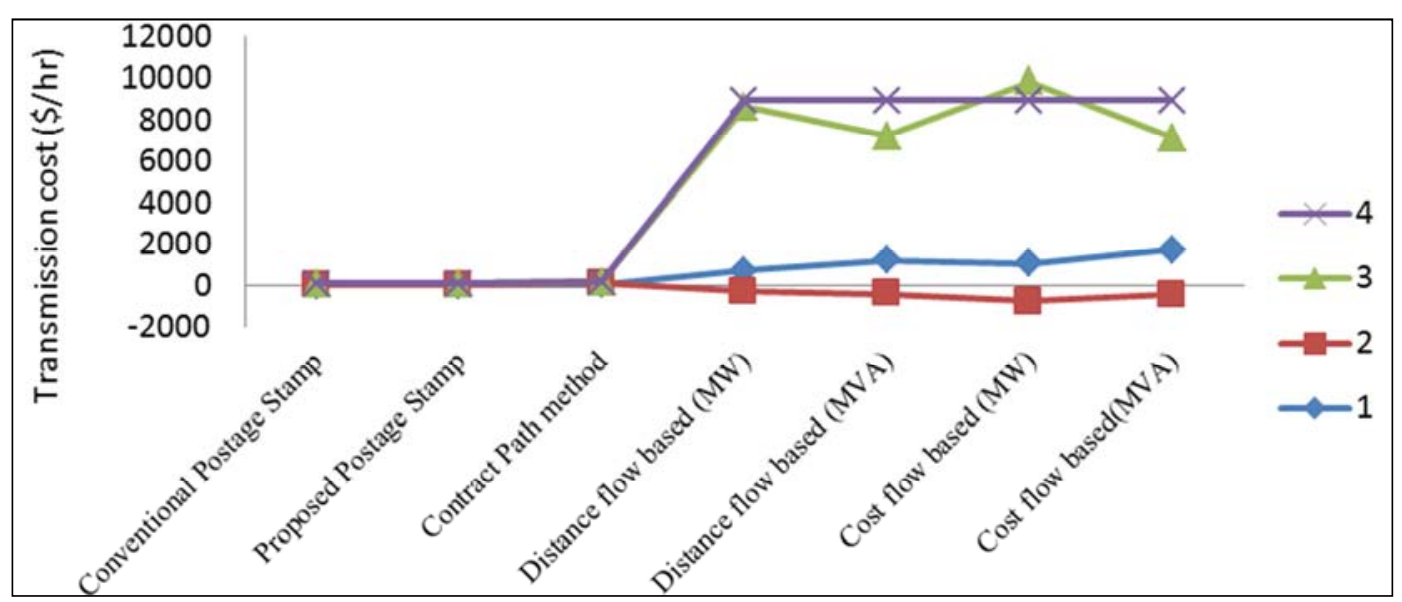

Fig. 4. Results for the 18 bus system showing various transmission pricing methods.

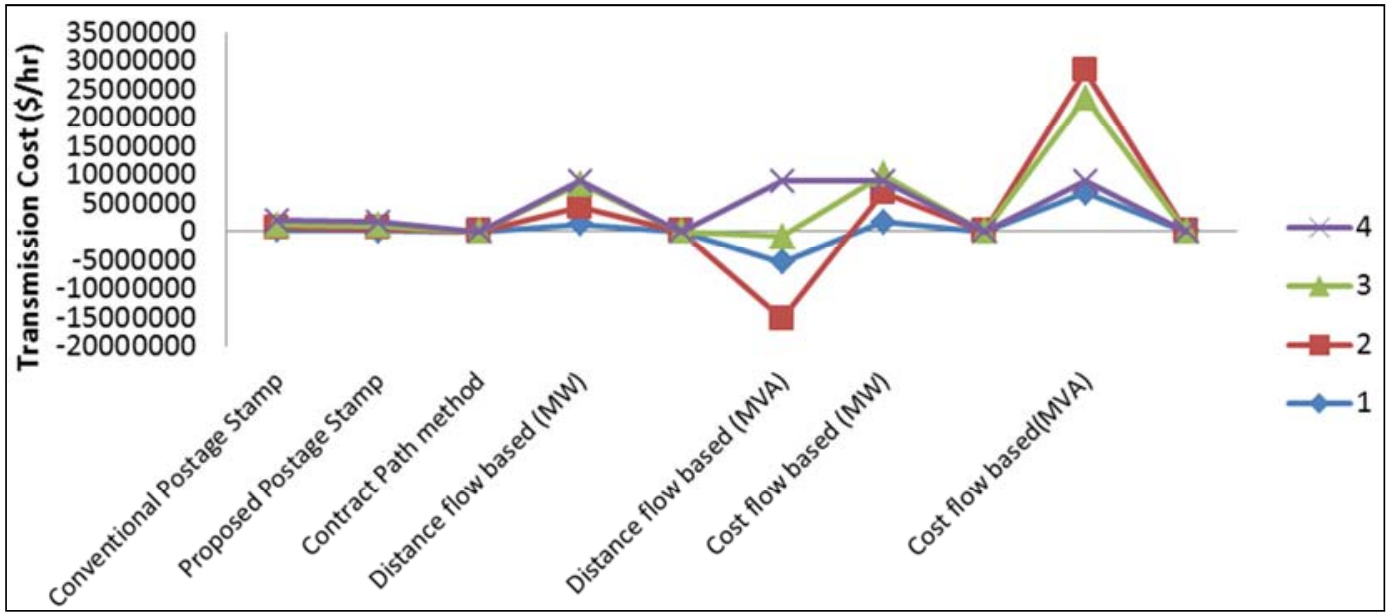

Fig. 5. Result for the IEEE -30 bus test system showing various transmission pricing methods. 
Table 4. IEEE- 30 bus test system result for all four transactions.

\begin{tabular}{llll}
\hline \multirow{2}{*}{ Transmission Pricing Method (\$/hr) } & \multicolumn{3}{l}{ Transaction No. } \\
\cline { 2 - 4 } & $\mathbf{1}$ & $\mathbf{2}$ & $\mathbf{3}$ \\
\hline Conventional Postage Stamp & 273717.1 & 404324.6 & 531014.5 \\
Proposed Postage Stamp & 237544.3 & 352298.3 & 464465.6 \\
Contract Path method & 3723.633 & 8120.156 & 7759.688 \\
Distance flow based (MW) & $1,342,305$ & $2,963,791$ & $4,053,725$ \\
Distance flow based (MVA) & $-5,375,019$ & $-9,859,243$ & $14,422,030$ \\
Cost flow based (MW) & $1,758,364$ & $5,130,107$ & $3,190,208$ \\
Cost flow based(MVA) & $6,776,375$ & $21,477,698$ & $-4,691,893$ \\
\hline
\end{tabular}

Tables 3 and 4 is a comparison of all the methods discussed in section II for the eighteen and the thirty bus test systems respectively and shown graphically in Figures 4 and 5 .

From Figures 4 and 5 we can see that for the conventional postage stamp, proposed postage stamp and contract path transmission pricing methods, the prices remained fairly low. The distance flow based and cost flow based transmission pricing methods experienced some upshots and dips at some points showing dynamism in price, as a result of load flow analysis been involved in the computation of the distance flow based (MW \& MVA) transmission pricing method and Cost flow based (MW \& MVA) transmission pricing method. In Figure 4, transactions $3 \& 4$ have both real and reactive power component in the transactions so that brought about the upshot for the distance and flow based approaches. It can also be seen that the MVA variants for the distance flow based and the cost flow based methods for transaction 3 are lower than that of the MW variant, this shows that since the MVA variant incorporates both real and reactive power components it produced a better result unlike the MW variant. In Figure 5, although transaction 2 and 3 had less real power transacted than transaction 4 their path of transaction actually stressed the system resulting in their being charged more in the cost flow based methods of transmission pricing.

\section{Conclusion}

In this paper, various transmission-pricing methods were reviewed with particular attention given to the embedded cost transmission methods. A computational evaluation of four different embedded transmission-pricing methods was carried out. Result showed that distance flow-based and cost flowbased methods, which required detailed load flow analysis, and power flow simulations gave higher prices due to the transmission line cost factors. The third scheme was the contract path method which is simpler using pure computation gave lower cost than the other two, but it is not so much used due to the fact that it only consider the transaction path.

The fourth technique evaluated was the postage stamp method which gave the least cost, and was faster to compute when compared with the distance and cost flow methods. Its major weakness was the fact that reactive power component is not considered in this approach and therefore technically not paid for despite its usefulness in grid stability. In view of this, a new approach to solving transmission pricing involving both real and reactive power transfer from one bus to another using the postage stamp approach was developed and proposed in this work. Results obtained showed slightly increased cost when compared with the conventional method due to payment for reactive power.

This paper shows the possibility of solving the transmission pricing problem for both real and reactive power using the postage stamp approach which could make for more efficient transmission use, as all the network grid is considered as been used in the various transactions. The distance flow based approach and the cost flow based method had larger values as the length of the transmission lines and the estimated cost of the various transmission lines were used in computation. The Methods were implemented and simulated using MATLAB Programming. In the opinion of the authors the proposed postage stamp method gave a better tariff to consumers since the cost of the transmission is not to be recouped in the short term rather it is a long term concern and would encourage the use of the entire network. It also rewards those who bring about stability to the transmission grid. 


\section{Appendix}

Appendix 1. Distance flow Based method for 18 bus test system (MW and MVA).

\begin{tabular}{|c|c|c|c|c|c|c|c|c|c|}
\hline \multicolumn{2}{|c|}{ Trxm. lines } & \multicolumn{2}{|c|}{ Transaction 1} & \multicolumn{2}{|c|}{ Transaction 2} & \multicolumn{2}{|c|}{ Transaction 3} & \multicolumn{2}{|c|}{ Transaction 4} \\
\hline Orig bus & Dest. bus & MW & MVA & MW & MVA & MW & MVA & MW & MVA \\
\hline 1 & 2 & 333.8758 & 261.3777 & -421.01 & -331.571 & 369.1663 & 302.8509 & -53.6349 & -50.445 \\
\hline 3 & 4 & -29.233 & 22.8844 & 36.86216 & -29.03 & -32.3235 & 26.5155 & 4.696462 & -4.41661 \\
\hline 3 & 6 & -86.1603 & 67.44875 & 108.6464 & -85.5621 & -95.2692 & 78.15095 & 13.8422 & -13.0174 \\
\hline 3 & 7 & 1118.686 & 843.0642 & -1410.75 & -1068.6 & 1236.535 & 965.2961 & -179.482 & -155.745 \\
\hline 4 & 5 & 4.584779 & 3.455181 & -5.78176 & -4.37952 & 5.067766 & 3.956131 & -0.73558 & -0.6383 \\
\hline 4 & 7 & -1730.7 & -1269.01 & 1881.639 & 1379.676 & 5334.311 & 3911.284 & -46.6081 & -34.1745 \\
\hline 6 & 7 & 163.946 & 139.3485 & -177.391 & -151.836 & 417.5501 & 333.7217 & -32.8015 & -32.5503 \\
\hline 6 & 7 & 63.8727 & 50.118 & -75.6363 & -59.4692 & 108.0495 & 84.70804 & 124.209 & 97.57082 \\
\hline 7 & 8 & 294.1013 & 231.4419 & 155.3186 & 79.88772 & 325.4634 & 268.5477 & -47.4049 & -44.892 \\
\hline 7 & 17 & 31.42432 & 24.35508 & -37.055 & -28.7799 & 44.01022 & 34.32761 & 57.45016 & 44.67491 \\
\hline 7 & 17 & 254.7274 & 194.057 & -308.859 & -236.214 & 381.2545 & 291.5737 & 664.2315 & 519.0755 \\
\hline 8 & 9 & 170.0307 & 129.3021 & -206.192 & -157.392 & 254.5204 & 194.2784 & 443.7501 & 345.865 \\
\hline 9 & 10 & 123.853 & 93.90999 & -312.317 & -225.798 & 174.9783 & 133.7256 & 433.3901 & 299.7832 \\
\hline 10 & 11 & 58.62511 & 42.61858 & -35.8441 & -28.4747 & 90.84671 & 65.15111 & 120.8129 & 87.54742 \\
\hline 11 & 12 & 206.3012 & 152.2733 & -124.503 & -101.738 & 320.325 & 232.7805 & 425.3972 & 312.801 \\
\hline 12 & 13 & 64.22157 & 49.43349 & -162.105 & -118.427 & 90.71549 & 70.43872 & 224.8956 & 156.5299 \\
\hline 13 & 14 & 28.93912 & 13.40948 & -73.1089 & -21.335 & 40.87135 & 19.98436 & 101.4072 & 27.6537 \\
\hline 13 & 14 & 28.87164 & 0.886496 & -73.0059 & 10.85583 & 40.76983 & 2.43494 & 101.2638 & -16.6019 \\
\hline 13 & 14 & 31.75222 & 1.013053 & 41.77881 & -19.9784 & 44.83034 & 2.752236 & 111.4795 & -18.5307 \\
\hline 14 & 15 & 79.36437 & -45.0336 & 104.7064 & -82.5532 & 112.0353 & -62.3484 & -357.26 & 332.1255 \\
\hline 14 & 17 & -116.613 & -78.1158 & 70.43614 & 44.9788 & 73.46535 & 82.42043 & -240.329 & -161.09 \\
\hline 15 & 16 & -45.8313 & -30.723 & 27.66752 & 17.69017 & 29.09342 & 32.41598 & -94.4559 & -63.3566 \\
\hline 15 & 18 & -118.601 & -79.9547 & 71.29736 & 46.03766 & 79.5907 & 84.36072 & -244.462 & -164.882 \\
\hline 17 & 18 & -95.3436 & -64.4998 & 56.43187 & 37.48975 & -147.781 & -106.179 & -196.644 & -132.805 \\
\hline 1 & 5 & -471.527 & 149.2539 & 286.462 & -129.201 & -732.279 & 214.0238 & -971.571 & 320.0078 \\
\hline 1 & 5 & 0.084255 & 7.604494 & -0.09894 & -8.92819 & 0.251352 & 22.68958 & 0.168886 & 15.24414 \\
\hline 2 & 6 & -182.181 & -92.6817 & 107.8793 & 44.6962 & -282.464 & -143.554 & -375.753 & -191.107 \\
\hline 2 & 6 & 184.7281 & 138.5366 & -109.886 & -84.1032 & 286.529 & 214.7983 & 381.0816 & 285.6038 \\
\hline
\end{tabular}

Appendix 2. Cost flow Based method comparison for 18 bus test system (MW and MVA).

\begin{tabular}{|c|c|c|c|c|c|c|c|c|c|}
\hline \multicolumn{2}{|c|}{ Trxm. Lines } & \multicolumn{2}{|c|}{ Transaction 1} & \multicolumn{2}{|c|}{ Transaction 2} & \multicolumn{2}{|c|}{ Transaction 3} & \multicolumn{2}{|c|}{ Transaction 4} \\
\hline Orig bus & Dest. bus & MW & MVA & MW & MVA & MW & MVA & MW & MVA \\
\hline 1 & 2 & 793.7156 & 464.1841 & -1000.86 & -588.841 & 877.611 & 537.8369 & -127.505 & -89.586 \\
\hline 3 & 4 & -34.7474 & 20.32035 & 43.81581 & -25.7774 & -38.421 & 23.54461 & 5.582398 & -3.92176 \\
\hline 3 & 6 & -102.413 & 59.89156 & 129.1413 & -75.9755 & -113.241 & 69.39464 & 16.45338 & -11.5589 \\
\hline 3 & 7 & 1329.714 & 748.6043 & -1676.87 & -948.874 & 1469.794 & 857.141 & -213.339 & -138.295 \\
\hline 4 & 5 & 5.449647 & 3.06805 & -6.87243 & -3.88883 & 6.023744 & 3.512873 & -0.87434 & -0.56678 \\
\hline 4 & 7 & -2057.18 & -1126.82 & 2236.59 & 1225.092 & 6340.57 & 3473.05 & -55.4002 & -30.3455 \\
\hline 6 & 7 & 194.8726 & 123.7354 & -210.854 & -134.824 & 496.3163 & 296.3304 & -38.9892 & -28.9032 \\
\hline 6 & 7 & 75.92158 & 44.5026 & -89.9042 & -52.806 & 128.4319 & 75.21705 & 147.6396 & 86.63865 \\
\hline 7 & 8 & 349.5802 & 205.5103 & 184.6178 & 70.93682 & 386.8585 & 238.4587 & -56.3474 & -39.8621 \\
\hline 7 & 17 & 37.35217 & 21.62625 & -44.045 & -25.5553 & 52.31227 & 30.48143 & 68.2875 & 39.66938 \\
\hline 7 & 17 & 302.7789 & 172.3142 & -367.122 & -209.748 & 453.174 & 258.9048 & 789.5315 & 460.9165 \\
\hline 8 & 9 & 202.1052 & 114.8146 & -245.088 & -139.757 & 302.5329 & 172.5107 & 527.4587 & 307.1131 \\
\hline 9 & 10 & 147.2165 & 83.38799 & -371.233 & -200.499 & 207.9861 & 118.7425 & 515.1444 & 266.1944 \\
\hline 10 & 11 & 69.68409 & 37.84344 & -42.6057 & -25.2843 & 107.9839 & 57.85136 & 143.603 & 77.7383 \\
\hline 11 & 12 & 245.2176 & 135.212 & -147.989 & -90.3389 & 380.7508 & 206.699 & 505.6437 & 277.7537 \\
\hline 12 & 13 & 76.33627 & 43.89479 & -192.685 & -105.158 & 107.828 & 62.54652 & 267.3198 & 138.9918 \\
\hline 13 & 14 & 34.39817 & 11.90703 & -86.9001 & -18.9445 & 48.58128 & 17.74524 & 120.5366 & 24.55528 \\
\hline 13 & 14 & 34.31796 & 0.787169 & -86.7776 & 9.639503 & 48.46061 & 2.162121 & 120.3661 & -14.7417 \\
\hline 13 & 14 & 37.74193 & 0.899547 & 49.65993 & -17.7399 & 53.28709 & 2.443866 & 132.5089 & -16.4545 \\
\hline 14 & 15 & 94.33559 & -39.9879 & 124.4581 & -73.3037 & 133.1695 & -55.3626 & -424.653 & 294.913 \\
\hline 14 & 17 & -138.611 & -69.3634 & 83.72314 & 39.93922 & 87.32378 & 73.18576 & -285.665 & -143.04 \\
\hline 15 & 16 & -54.4769 & -27.2807 & 32.8867 & 15.70811 & 34.58158 & 28.78398 & -112.274 & -56.2579 \\
\hline 15 & 18 & -140.974 & -70.9963 & 84.74683 & 40.87944 & 94.60462 & 74.90866 & -290.576 & -146.408 \\
\hline 17 & 18 & -113.329 & -57.273 & 67.07713 & 33.28927 & -175.658 & -94.2827 & -233.739 & -117.925 \\
\hline 1 & 5 & -1121.11 & 265.0995 & 681.0965 & -229.482 & -1741.08 & 380.1417 & -2310.02 & 568.3867 \\
\hline 1 & 5 & 0.200326 & 13.50684 & -0.23524 & -15.8579 & 0.597618 & 40.30045 & 0.401545 & 27.07612 \\
\hline 2 & 6 & -433.158 & -164.618 & 256.4954 & 79.38783 & -671.591 & -254.976 & -893.395 & -339.438 \\
\hline 2 & 6 & 439.2125 & 246.0639 & -261.267 & -149.381 & 681.2559 & 381.5173 & 906.0655 & 507.2795 \\
\hline
\end{tabular}


Appendix 3. Distance flow Based method result for IEEE-30 bus test system (MW and MVA).

\begin{tabular}{|c|c|c|c|c|c|c|c|c|c|}
\hline \multicolumn{2}{|c|}{ Trxm. Lines } & \multicolumn{2}{|c|}{ Transaction 1} & \multicolumn{2}{|c|}{ Transaction 2} & \multicolumn{2}{|c|}{ Transaction 3} & \multicolumn{2}{|c|}{ Transaction 4} \\
\hline Origbus & Destbus & MW & MVA & MW & MVA & MW & MVA & MW & MVA \\
\hline 1 & 2 & 13135 & -60782 & 59895 & -277160 & 1812 & -8385 & -36891 & 170707 \\
\hline 1 & 3 & -22238 & 101164 & -126499 & 580601 & -11074 & 53231 & 39130 & -196187 \\
\hline 2 & 4 & -41678 & 187263 & 163 & -5268 & -18286 & 85924 & 101616 & -477529 \\
\hline 2 & 5 & 29070 & -131532 & 62187 & -281366 & 7813 & -35351 & -69081 & 312599 \\
\hline 2 & 6 & 54091 & -244737 & 116823 & -528968 & 16765 & -76598 & -147415 & 676613 \\
\hline 3 & 4 & -4760 & 21739 & 193501 & -875924 & -2356 & 10358 & 8286 & -34377 \\
\hline 4 & 6 & 86509 & -381099 & 104329 & -472705 & 32080 & -139696 & -228041 & 1010200 \\
\hline 5 & 7 & 51495 & -229085 & 93500 & -413933 & -41632 & 186461 & 280517 & -1230422 \\
\hline 6 & 7 & 11187 & 33366 & 23936 & 77748 & 3006 & 20866 & -26568 & -179119 \\
\hline 6 & 8 & -5879 & 26197 & -12596 & 56381 & -1608 & 7668 & 14179 & -66693 \\
\hline 6 & 28 & 6164 & -40919 & 6035 & -47448 & 54994 & -251233 & -597556 & 2741022 \\
\hline 8 & 28 & 81340 & -353501 & 78237 & -376860 & 735164 & -2011881 & -181666 & 778582 \\
\hline 9 & 10 & 151665 & -631156 & 219805 & -918278 & -254442 & 1066310 & 268430 & -1192729 \\
\hline 9 & 11 & 163587 & -746007 & 237160 & -1080023 & -273864 & 1266853 & 290420 & -1307681 \\
\hline 10 & 17 & 8585 & 36211 & 8389 & 53806 & 76840 & 270512 & 150267 & 430905 \\
\hline 10 & 20 & 288283 & -1335842 & 417801 & -1919107 & -483640 & 2311227 & 510228 & -2083564 \\
\hline 10 & 21 & 0 & -75555 & 0 & -103188 & 0 & 160117 & 0 & 19224 \\
\hline 10 & 22 & -73377 & 247044 & -65655 & 223809 & 140284 & -376052 & 331256 & -294398 \\
\hline 12 & 13 & -33517 & 134450 & 546093 & -1546751 & 96682 & -376051 & 168856 & -578477 \\
\hline 12 & 14 & 251838 & -1126987 & -30182 & 107902 & 231643 & -843362 & 38250 & -155258 \\
\hline 12 & 15 & 248371 & -730552 & -26570 & 77552 & 208143 & -378079 & 35864 & -116046 \\
\hline 12 & 16 & 0 & 12664 & 0 & -150692 & 0 & 144733 & 2315589 & 7165371 \\
\hline 14 & 15 & 29917 & -118921 & 73550 & -300939 & -2977 & 19533 & -101310 & 401718 \\
\hline 15 & 18 & 131764 & -537705 & 317923 & -1341477 & -8671 & 74335 & -456619 & 1857303 \\
\hline 15 & 23 & 99962 & -384646 & 89485 & -350347 & -192527 & 793884 & -457289 & 1879951 \\
\hline 16 & 17 & 28269 & -96075 & 69499 & -221218 & -2777 & 19903 & -95649 & 387276 \\
\hline 18 & 19 & 30758 & -126409 & 252187 & -936756 & -89306 & 381847 & -156636 & 665218 \\
\hline 19 & 20 & 33894 & -113236 & -11436 & 45609 & 43491 & -114333 & -89772 & 337410 \\
\hline 21 & 22 & 11519 & -44044 & 10308 & -40311 & -22109 & 93930 & -52404 & 226120 \\
\hline 22 & 24 & 42182 & -170334 & 347267 & -169399 & -122164 & 529299 & -214070 & 937204 \\
\hline 23 & 24 & 63428 & 251023 & 523496 & 2250085 & -183414 & -689055 & -321156 & -1011737 \\
\hline 24 & 25 & 320850 & 1386035 & -38598 & -71019 & 295874 & 1111575 & 48812 & 162122 \\
\hline 25 & 26 & -381933 & 1528260 & -121230 & 424337 & 944020 & -1234199 & 159807 & -584336 \\
\hline 25 & 27 & 103369 & -214159 & -34808 & 131587 & 132848 & -96234 & -272771 & 1086262 \\
\hline 27 & 29 & -208089 & -470883 & -200708 & -537396 & 1297813 & 5886799 & -365382 & -628796 \\
\hline 27 & 30 & 23 & -176 & 16 & -122 & 169 & -1274 & -35 & 260 \\
\hline 29 & 30 & -227481 & -976091 & -219511 & -922005 & 1445133 & 6558450 & -399009 & -1444475 \\
\hline 4 & 12 & 0 & 0 & 0 & 0 & 0 & 0 & 0 & 0 \\
\hline 6 & 9 & 0 & 0 & 0 & 0 & 0 & 0 & 0 & 0 \\
\hline 6 & 10 & 0 & 0 & 0 & 0 & 0 & 0 & 0 & 0 \\
\hline 28 & 27 & 0 & 0 & 0 & 0 & 0 & 0 & 0 & 0 \\
\hline
\end{tabular}


Appendix 4. Cost flow Based method results for IEEE-30 bus test system (MW and MVA).

\begin{tabular}{|c|c|c|c|c|c|c|c|c|c|}
\hline \multicolumn{2}{|c|}{ Transmission Lines } & \multicolumn{2}{|c|}{ Transaction 1} & \multicolumn{2}{|c|}{ Transaction 2} & \multicolumn{2}{|c|}{ Transaction 3} & \multicolumn{2}{|c|}{ Transaction 4} \\
\hline Orig. bus & Dest bus & MW & MVA & MW & MVA & MW & MVA & MW & MVA \\
\hline 1 & 2 & 33497 & 143951 & 152741 & 656399 & 4621 & 19858 & -94078 & -404286 \\
\hline 1 & 3 & -27983 & -118219 & -159177 & -678483 & -13934 & -62206 & 49238 & 229262 \\
\hline 2 & 4 & -82580 & -344580 & 322 & 9694 & -36232 & -158108 & 201340 & 878696 \\
\hline 2 & 5 & 71575 & 300759 & 153114 & 643366 & 19236 & 80833 & -170087 & -714783 \\
\hline 2 & 6 & 34941 & 146820 & 75465 & 317332 & 10829 & 45952 & -95226 & -405906 \\
\hline 3 & 4 & -59433 & -252080 & 2416130 & 10157210 & -29424 & -120107 & 103468 & 398635 \\
\hline 4 & 6 & 731904 & 2994341 & 8826707 & 3714094 & 271411 & 1097609 & -1929326 & -7937261 \\
\hline 5 & 7 & 52373 & 216376 & 95094 & 390969 & -42342 & -176117 & 285300 & 1162160 \\
\hline 6 & 7 & 11991 & -33215 & 25657 & -77396 & 3222 & -20772 & -28478 & 178308 \\
\hline 6 & 8 & -9919 & -41050 & -21253 & -88349 & -2713 & -12016 & 23924 & 104508 \\
\hline 6 & 28 & 14640 & 90249 & 14332 & 104647 & 130603 & 554096 & -1419110 & -6045341 \\
\hline 8 & 28 & 14907 & 60165 & 14338 & 64140 & 134730 & 342415 & -33293 & -132512 \\
\hline 9 & 10 & 78042 & 301611 & 113104 & 438819 & -130927 & -509559 & 138125 & 569971 \\
\hline 9 & 11 & 492855 & 2087299 & 714517 & 3021862 & -825101 & -3544605 & 874980 & 3658842 \\
\hline 10 & 17 & 8099 & -31727 & 7915 & -47142 & 72493 & -237011 & 141767 & -377540 \\
\hline 10 & 20 & 156083 & 671681 & 226207 & 964956 & -261854 & -1162119 & 276250 & 1047647 \\
\hline 10 & 21 & 0 & 101549 & 0 & 138690 & 0 & -215205 & 0 & -25839 \\
\hline 10 & 22 & -64517 & -201725 & -57727 & -182752 & 123346 & 307067 & 291258 & 240392 \\
\hline 12 & 13 & -2444 & -9105 & 39820 & 104742 & 7050 & 25465 & 12312 & 39173 \\
\hline 12 & 14 & 20093 & 83503 & -2408 & -7995 & 18481 & 62488 & 3052 & 11504 \\
\hline 12 & 15 & 126031 & 344269 & -13483 & -36546 & 105618 & 178168 & 18198 & 54686 \\
\hline 12 & 16 & 0 & -7154 & 0 & 85125 & 0 & -81758 & 1408495 & -4047651 \\
\hline 14 & 15 & 12610 & 46552 & 31002 & 117803 & -1255 & -7646 & -42703 & -157253 \\
\hline 15 & 18 & 32773 & 124205 & 79076 & 309869 & -2157 & -17171 & -113574 & -429020 \\
\hline 15 & 23 & 33684 & 120370 & 30153 & 109636.3 & -64875 & -248435 & -154091 & -588305 \\
\hline 16 & 17 & 14574 & 45997 & 35829 & 105911 & -1431 & -9529 & -49310 & -185414 \\
\hline 18 & 19 & 37917 & 144718 & 310885 & 1072441 & -110093 & -437155 & -193094 & -761572 \\
\hline 19 & 20 & 62632 & 194326 & -21132 & -78271 & 80366 & 196210 & -165889 & -579038 \\
\hline 21 & 22 & 54983 & 195249 & 49206 & 178699 & -105537 & -416393 & -250145 & -1002392 \\
\hline 22 & 24 & 6415 & 24055 & 52808 & 23923 & -18577 & -74749 & -32553 & -132354 \\
\hline 23 & 24 & 10332 & -37974 & 85274 & -340388 & -29877 & 104239 & -52314 & 153053 \\
\hline 24 & 25 & 138481 & -555560 & -16659 & 28466 & 127701 & -445549 & 21068 & -64983 \\
\hline 25 & 26 & -139390 & -517980 & -44244 & -143822 & 344530 & 418312 & 58323 & 198052 \\
\hline 25 & 27 & 27983 & 53841 & -9423 & -33082 & 35964 & 24194 & -73843 & -273094 \\
\hline 27 & 29 & -54208 & 113920 & -52286 & 130012 & 338088 & -1424188 & -95184 & 152124 \\
\hline 27 & 30 & 2 & 17 & 2 & 12 & 17 & 120 & -4 & -25 \\
\hline 29 & 30 & -73432 & 292618 & -70859 & 276404 & 466496 & -1966127 & -128802 & 433032 \\
\hline 4 & 12 & 5 & 30 & 1 & 5 & 1200473 & 2350531 & -79 & -488 \\
\hline 6 & 9 & 3 & 20 & 1 & 3 & 956607 & 762050 & -56 & -328 \\
\hline 6 & 10 & -7154 & 28249 & -6902 & 26698 & -64655 & 275061 & -12518 & 45228 \\
\hline 28 & 27 & 1 & 3 & 0 & 1 & 479311 & -190037 & -10 & -54 \\
\hline
\end{tabular}

\section{References}

[1] M. Murali, M. S. Kumari \& M. Sydulu, “A comparison of fixed cost based transmission pricing methods", Journal of electrical and electronic engineering, Scientific and Academic Publishing Vol. 1, Issue 1, 2011, pp. 33-41.

[2] R. Abhyankar, S. A. Soman, S. A. Khaparde, "Optimization approach to real power tracing: an application to transmission fixed cost allocation”, IEEE Trans. on Power Systems, Vol. 21, Issue 3, 2006, pp. 1350-1361.

[3] O. Pop, M. Nemeş, "Power transmission allocation with network matrices", The 7th International Power Systems Conference, Timişoara, Romania, 2007, pp. 527-534.

[4] T. Krause, "Evaluation of transmission pricing methods for liberalized markets: A literature survey", Internal report from ETH Zurich, 2003, pp. 1-24.

[5] S. Matetic, "Intelligent trading agent for power trading through tariff market", M. Sc Thesis, University of Zagreb, 2013, pp. 19-22.

[6] L. Similia, G. Koreneff \& V. Kekkonen, "Network tariff structures in smart grid environment", VTT Technical Report, Finland, 2011.

[7] A. T. Haral \& M. F. Aslam, "Analysis of spot prices Arrangements in deregulated electricity", International Conference on Electrical Engineering, ICEE'07, 1, 2007, pp. $1-6$.

[8] A. K. Singh, C. Singh, S. Kumar, \& Y. R Sood, "Electricity pricing in deregulated power sector", International Journal of Advanced Research in Electrical Electronic and Instrumentation Engineering, Vol. 3, Issue 5, 2014, pp. 93339339.

[9] M. Shalini, \& K. V. Kishore, "Comparison of embedded type transmission cost allocation methods", International Journal of Scientific Engineering and Technology Research, Vol. 3, Issue. 37, 2014, pp. 7526-7529. 
[10] D. Shirmohammadi, X. Vieira, B. Gorenstin, M. V. P Pereira, "Some fundamental technical concepts about cost based transmission pricing", IEEE Trans. on Power Systems. Vol. 11, Issue 2, 1996.

[11] I. Leevongwat, \& P. Rostgoufard, "Forecasting locational marginal pricing in deregulated power markets", Power Systems Conference and Exposition, PSCE '09. IEEE/PES, Vol. 1, 2009, pp. 1-9.

[12] B. J. Ring, "Dispatch based pricing in decentralized power systems", Doctoral Dissertation, University of Canterbury, Christchurch, New Zealand, 1995, pp. 15.

[13] M. Sahni, R. Jones \& Y. Cheng, "Locational marginal price forecasting and predictive operations in U. S. power markets", IEEE Power \& Energy Magazine, 2012, pp. 35-37.

[14] A. Bansal, C. Srivastava \& A. Saini, "Transmission cost allocation of bilateral transaction in deregulated power system", International Journal of Electrical and Electronics Engineering, Vol. 4, Issue 10, 2013, pp. 10303-10310.

[15] Manitoba HVDC Research Centre, PSCAD: IEEE 30 bus System, 2014 [online] available https:/hvdc.ca> knowledge_base $>$ ieee_30_bus_technical_note.pdf. Accessed 10-09-201̄.

[16] R. Gnanadass \& N. P Padhy, "A new approach for transmission embedded cost allocation in restructured power market", Journal of Energy and Environment, Vol. 1, Issue 4, 2005, pp. 37-47.

[17] H. Saadat, Power System Analysis, (WCB/Mc-Graw Hill Publishers, 1999, pp. 224-227.

[18] R. Rajathy, "Investigations on power system operation and management in restructured market" A Ph. D Thesis Submitted to the Pondicherry University, India, 2011, pp. 130131. 